\title{
Dental help for the homeless
}

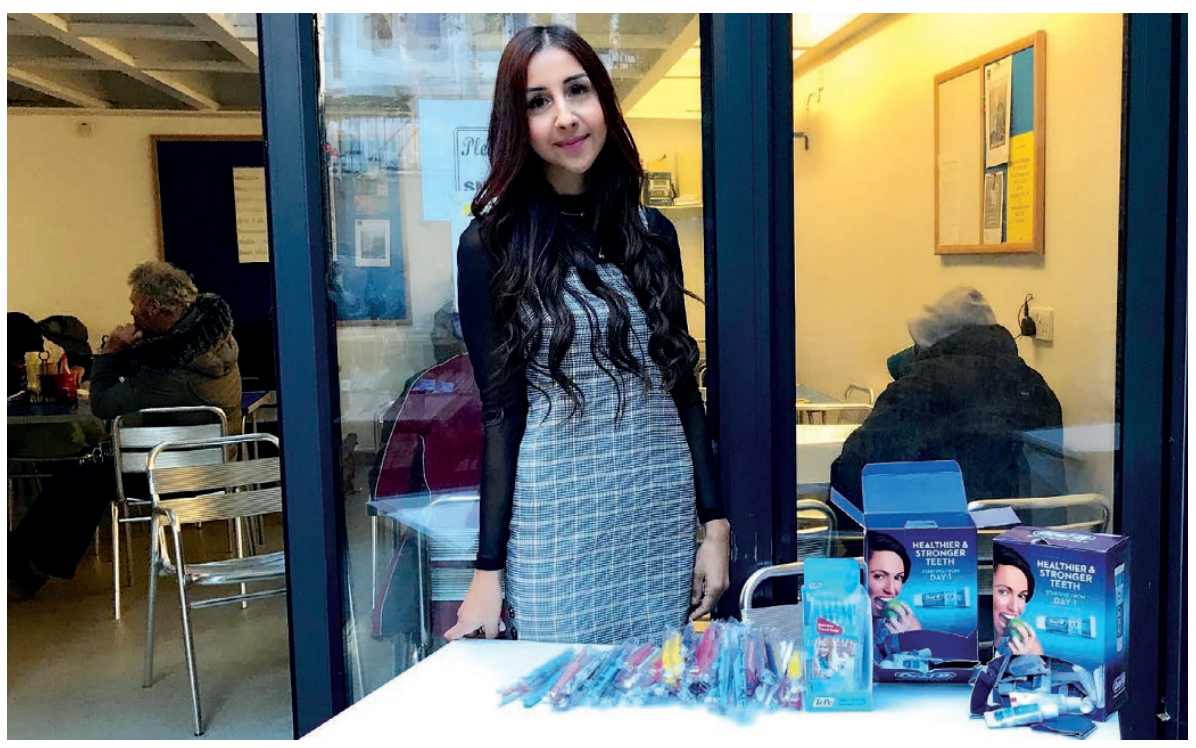

Homeless people in dire need of dental advice to improve their health and help them get back to a normal working life are being given a lifeline by newly-qualified dentist $\mathrm{Dr}$ Vian Shathur.

Shathur, aged 26, qualified as a dentist from the University of Cardiff in June 2018 and, since starting to work in London, she has been helping out at a soup kitchen run by the American International Church in central London, once a week at weekends for homeless people.

'I got in contact with the soup kitchen here in London and because I'm qualified now, I can use my qualification and try and do something with it,' said Shathur. 'I'd done work with homeless people in the past and I know there's a huge need there. They are lovely people who just need someone to listen to them.'

The role has been advisory so far, focusing on oral hygiene, as she explains: 'It's mainly been from a prevention standpoint at the moment.

'I've just been doing oral hygiene instruction and then talking to people about where they can go if they have any emergency problems. If they are seeking accommodation in certain homeless shelters, as long as they've got temporary accommodation, I've been telling them I am more than happy for them to come and see me and to treat them at my practice.

'The more awareness I raise, the more I am hoping to be able to do at the soup kitchen, starting with examination with fluoride and maybe we can get on to doing simple extractions. It's a long-term goal.
'You notice that a lot of the people there have neglected seeing a dentist completely. Essentially, they just have black stumps everywhere and a lot of people complain of pain and many can't eat easily. It has affected them getting jobs and getting off the street as well.

'They are in this cycle where their teeth look a certain way so they are judged when they go to interviews and they don't get jobs so they end up still on the streets.'

There was little support for homeless people to see a dentist, she explained, because to be seen on the NHS meant dentists had to legally require an address from them and many did not have one or any money.

Shathur is keen to encourage other dentists to help in a similar way, adding: 'It's just me at the moment but I am hoping that with more interest and support from larger dental companies, it will become something which a lot of people can volunteer into.'

Alexander Brown, Director of the Soup Kitchen at the American International Church, said: 'Dr Vee, as our guests affectionately know her, has been a vital part of The Soup Kitchen over the last few months.

'When she initially reached out to us about volunteering, I was so happy to discover that she was a dentist. Oral health is something that is a constant concern in the homeless community and something we've wanted to address for some time.

'Many rough sleepers don't know how or where to access dental health services and Vee has been a fantastic resource for us. She's already referred several of our guests for treatment.' 